\section{Guidance for Integrated Behavioral Health in Primary Care: Responding to a Proposed Curriculum}

\section{TO THE EDITOR:}

We appreciated Dr Martin and colleagues' efforts to define the essential skills for family medicine residents practicing integrated behavioral health (IBH) in the March 2019 issue of Family Medicine. ${ }^{1}$ The resultant work identified 21 observable competencies related to the practice of IBH by family medicine residents. To put the level of guidance provided by Martin et al in context we searched the current Accreditation Council for Graduate Medical Education's (ACGME) Residency Review Committee (RRC) requirements for family medicine, internal medicine, and pediatrics to identify current standards for primary care residency training in IBH. We reviewed the documents by identifying all content using the search: "menta*," "behavi*," and "integrat*." Table 1 summarizes the findings.

While it would be cumbersome and impractical for the ACGME to provide the granularity of 21 observable competencies for all of the elements defining the scope of family medicine, it is striking how little guidance is provided within primary care for establishing best practices in IBH training. Only family medicine provides a requirement for programs to have faculty members dedicated to the integration of behavioral health into the educational program. Pediatrics requires exposure to faculty with subspecialty training in developmental-behavioral pediatrics, but this is less likely to align with the development of IBH training models than the language of the family medicine RRC requirements. The ability to shape primary care curricula rests in the relative prioritization of the multiple competing demands facing primary care educators. The burden facing the ACGME is to identify the core elements of primary care and to emphasize the elements with the strongest evidence base for improving patient-centered outcomes. IBH is an area where strong evidence suggests its implementation drives improved outcomes. We should work to improve the guidance provided to primary care educators in how to prioritize, implement, and measure the best practices of IBH.

Based on Martin et al's initial work, improving training in delivering team-based care and enhancing communication skills with interdisciplinary professionals are priorities consistent with essential practices that have been explicated for IBH. ${ }^{5}$ Enhanced guidance for IBH training could take several forms, including (1) changes to the RRC requirements for family medicine, internal medicine, and pediatrics; (2) the development of more detailed supplementary guidance from the ACGME based upon Martin and colleagues' 21 competencies explicating the core IBH elements and suggested strategies for their implementation; and/ or (3) enhanced opportunities for technical assistance and implementation support to build IBH training capacity. As programs gain experience integrating some or all of the identified IBH competencies into their training curricula, we need to support mechanisms for rigorous evaluation and wide-based dissemination of best practices to the field. Ultimately, we hope centralized training resources and pathways for real-time technical assistance will become available at a national level to support programs seeking to expand their IBH training. doi: 10.22454/FamMed.2019.607155

FINANCIAL SUPPORT: This publication was made possible by UH1HP29964 from the Health Resources and Services Administration (HRSA), an operating division of the US Department of Health and Human Services. Its contents are solely the responsibility of the authors and do not necessarily represent the official views of the HRSA or the US Department of Health and Human Services.

Peter F. Cronholm, MD, MSCE

University of Pennsylvania

Philadelphia, PA

\section{Courtney Benjamin Wolk, PhD}

Perelman School of Medicine, University of Pennsylvania Philadelphia, PA

\section{References}

1. Martin M, Allison L, Banks E, et al. Essential skills for family medicine residents practicing integrated behavioral health: a Delphi study. Fam Med. 2019;51(3):227-233.

2. Accreditation Council for Graduate Medical Education ACGME Program Requirements for Graduate Medical Education in Internal Medicine, 2017.

3. Accreditation Council for Graduate Medical Education ACGME Program Requirements for Graduate Medical Education in Pediatrics, 2017.

4. Accreditation Council for Graduate Medical Education. ACGME Program Requirements for Graduate Medical Education in Family Medicine, 2018.

5. Substance Abuse and Mental Health Services Administration. SAMHSA-HRSA Center for Integrated Health Solutions. Essential elements of effective integrated primary care and behavioral health teams.https://www.integration. samhsa.gov/workforce/team-members/Essential_Elements of_an_Integrated_Team.pdf. Published March 2014. 
Table 1: Summary of RRC Content Related to Integrated Behavioral Health in Primary Care

\begin{tabular}{|c|c|}
\hline Specialty & Related RRC Content \\
\hline \multirow{5}{*}{ Family medicine ${ }^{2}$} & $\begin{array}{l}\text { II.B.10. There must be faculty members dedicated to the integration of } \\
\text { behavioral health into the educational program. }\end{array}$ \\
\hline & $\begin{array}{l}\text { IV.A.5.a).(1).(a).(iii) [must demonstrate competence to independently:] diagnose, } \\
\text { manage, and coordinate care for common mental illness and behavioral issues } \\
\text { in patients of all ages. }\end{array}$ \\
\hline & $\begin{array}{l}\text { IV.A.5.b) Medical Knowledge - Residents must demonstrate knowledge of } \\
\text { established and evolving biomedical, clinical, epidemiological and social- } \\
\text { behavioral sciences, as well as the application of this knowledge to patient care. }\end{array}$ \\
\hline & $\begin{array}{l}\text { IV.A.6.n) The curriculum must be structured so behavioral health is integrated } \\
\text { into the residents' total educational experience, to include the physical aspects } \\
\text { of patient care. }\end{array}$ \\
\hline & $\begin{array}{l}\text { IV.A.6.o) There must be a structured curriculum in which residents are } \\
\text { educated in the diagnosis and management of common mental illnesses. }\end{array}$ \\
\hline \multirow{5}{*}{ Pediatrics $^{3}$} & $\begin{array}{l}\text { Int.B. Pediatrics encompasses the study and practice of physical and mental } \\
\text { health promotion, disease prevention, diagnosis, care, and treatment of infants, } \\
\text { children, adolescents, and young adults during health and all stages of illness } \\
\ldots\end{array}$ \\
\hline & $\begin{array}{l}\text { II.B.9.a) This should include a faculty member in each of the following } \\
\text { subspecialty areas of pediatrics: } \\
\text { - II.B.9.a).(2) developmental-behavioral pediatrics. }\end{array}$ \\
\hline & $\begin{array}{l}\text { IV.A.5.a).(1).(d) interview patients and families about the particulars of the } \\
\text { medical condition for which they seek care, with specific attention to behavioral, } \\
\text { psychosocial, environmental, and family unit correlates of disease. }\end{array}$ \\
\hline & $\begin{array}{l}\text { IV.A.5.b) Medical Knowledge - Residents must demonstrate knowledge of } \\
\text { established and evolving biomedical, clinical, epidemiological and social- } \\
\text { behavioral sciences, as well as the application of this knowledge to patient care. }\end{array}$ \\
\hline & $\begin{array}{l}\text { IV.A.6.b).(3).(b) [a minimum of nine educational units of additional subspecialty } \\
\text { experiences, including:] developmental-behavioral pediatrics. }\end{array}$ \\
\hline Internal medicine ${ }^{4}$ & $\begin{array}{l}\text { IV.A.5.b) Medical Knowledge - Residents must demonstrate knowledge of } \\
\text { established and evolving biomedical, clinical, epidemiological and social- } \\
\text { behavioral sciences, as well as the application of this knowledge to patient care.. }\end{array}$ \\
\hline
\end{tabular}

Abbreviation: RRC, Residency Review Committee (of ACGME).

\section{Integration as Both Standard of Care and Standard of Training}

\section{TO THE EDITOR:}

We appreciate the recognition of our work by Drs Peter Cronholm and Benjamin Wolk, and their desire to start a discussion on strategies for accelerating workforce development in integrated behavioral health. Our team believes that integration (ie, interdisciplinary and team-based) should be the standard of care in the United States and the standard of training for graduate medical education (GME) in primary care.

The realities of patients with mental and behavioral health concerns seeking treatment, largely in primary care settings, are well documented. ${ }^{1-3}$ While recommendations for GME training in primary care have been promoted, no unifying standard exists. ${ }^{4}$ Additionally, while the Accreditation Council for Graduate Medical Education (ACGME) requires family medicine residents to receive training in the diagnosis and intervention of mental health concerns, no requirements or standards have been set related to working on or leading integrated teams. ${ }^{5}$ Although there are no required standards for integrated care training in family medicine, family medicine residencies appear to be on the forefront among primary care specialties in focusing on team-based holistic care. Thus, while we took a beginning step for training future FM residents in integrated care, much work is still needed to assess how the 21 competencies we identified apply to other specialties within the realm of primary care (eg, pediatrics, internal medicine, etc.) 
We agree with the excellent points Drs Cronholm and Wolk made about the vital role that accreditation bodies like the ACGME play in this discussion. The ACGME should provide clear direction on the skills that residents need to successfully work within interdisciplinary care teams. To date, that has not happened. Training programs also need easy access to a central repository of high-quality, competencybased modules as well as technical assistance for practice transformation that supports integration. We believe that such training and technical assistance should be financially supported by federal entities like Health Resources and Services Administration and the Substance Abuse and Mental Health Services Administration, not by the ACGME.

In addition to the next steps recommended by Drs Cronholm and Wolk, we propose four steps to accelerate workforce development for integrated care. First, develop a competencybased curriculum that residency training programs can adapt and use for their own needs. Our team has developed such a curriculum and preliminary data suggests that residents value the training and report higher knowledge and confidence in working in integrated behavioral health teams. Second, develop a validated measure of medical provider selfefficacy in behavioral health integration as a tool for developing personalized learning pathways and assessing performance. Third, determine the fit of our competencies with other primary care disciplines (eg, pediatrics, internal medicine, advanced practice providers). Our team is actively working on steps two and three. Fourth, involve national accreditation and workforce development bodies in making integrated care the standard of graduate medical training in primary care.

doi: 10.22454/FamMed.2019.733470
Matthew P. Martin, PhD, LMFT

Arizona State University

Phoenix, AZ

David Bauman, PsyD

Central Washington Family Medicine Residency Program

Yakima, WA

\section{Leslie Allison, MS, LMFT}

Methodist Healthcare Ministries

San Antonio, TX

Linda Myerholtz, PhD

University of North Carolina

Raleigh, NC

\section{References}

1. National Center for Health Statistics. Summary health statistics for US adults: National Health Interview Survey, 2011. Vital and Health Statistics, 10(256). https://www.cdc. gov/nchs/data/series/sr_10/sr10_256.pdf. Accessed June 4, 2019.

2. Pincus HA, Tanielian TL, Marcus SC, et al. Prescribing trends in psychotropic medications: primary care, psychiatry, and other medical specialties. JAMA. 1998;279(7):526-531.

3. Wang PS, Lane M, Olfson M, Pincus HA, Wells KB, Kessler RC. Twelve-month use of mental health services in the United States: results from the National Comorbidity Survey Replication. Arch Gen Psychiatry. 2005;62(6):629-640.

4. Schirmer JM, Taylor D, Zylstra R. New set of core principles of behavioral medicine. Leawood, KS: Society of Teachers of Family Medicine; 2008, https://connect.stfm.org/behavioralsciencebasics/curriculum/core-principles. Accessed June 4, 2019.

5. Baird MA, Hepworth J, Myerholtz L, Reitz R, Danner C. Fifty years of contributions of behavioral science in family medicine. Fam Med. 2017;49(4):296-303. https://experts.umn. edu/en/publications/fifty-years-of-contributions-of-behavioralscience-in-family-medi. Accessed June 4, 2019. 